\title{
Biodegradation of polyvinyl alcohol-low linear density polyethylene-blended plastic film by consortium of marine benthic vibrios
}

\author{
S. S. Raghul · S. G. Bhat $\cdot$ M. Chandrasekaran • \\ V. Francis $\cdot$ E. T. Thachil
}

Received: 14 March 2012/Revised: 14 March 2013/Accepted: 6 May 2013/Published online: 29 May 2013

(C) Islamic Azad University (IAU) 2013

\begin{abstract}
Marine bacteria, Vibrio alginolyticus and Vibrio parahemolyticus isolated from sediments were evaluated for their ability as a consortia, to degrade polyvinyl alcohol-low linear density polyethylene (PVA-LLDPE)blended plastic films in shake flask conditions at $120 \mathrm{rpm}$ at $37{ }^{\circ} \mathrm{C}$ over 15 weeks. Results indicated that relatively $20 \%$ decrease in tensile strength of the film could be achieved with 25 and $30 \%$ blend of PVA in the PVALLDPE plastic film compared to other ratios. Micrographs obtained with scanning electron microscope showed visible cracks and grooves on the surface of the PVA-LLDPE blend film after 15 weeks of incubation with bacterial consortium. The decrease in tensile strength of the PVAblended plastic films after treatment and the results of the scanning electron microscopic analysis evidence that the consortium could cause degradation of PVA-LLDPE plastic blends compared to suitable controls. This is the first report on polyvinyl alcohol degrading Vibrio sp. from marine sediments and its application in microbial degradation of polyvinyl alcohol-low linear density polyethylene plastic blends. The study indicated potential of marine benthic vibrios that have novel enzymes and unique
\end{abstract}

S. S. Raghul · S. G. Bhat $(\bowtie) \cdot$ M. Chandrasekaran Department of Biotechnology, Cochin University of Science and Technology, Kalamassery, Cochin 682022, Kerala, India e-mail: saritagbhat@gmail.com

M. Chandrasekaran

Department of Botany and Microbiology, College of Science, King Saud University, PB No. 2455, Riyadh 11451,

Kingdom of Saudi Arabia

V. Francis - E. T. Thachil

Department of Polymer Science and Rubber Technology, Cochin University of Science and Technology, Kalamassery, Cochin 682022, Kerala, India characteristics for application in bioremediation and solid waste management particularly in handling synthetic polymers such as PVA-blended plastic films.

Keywords Biodegradation - Low linear density polyethylene · Polyvinyl alcohol · Marine Vibrio sp

\section{Introduction}

Eco-friendly biodegradable plastics, which undergo degradation by the action of naturally occurring microorganisms such as bacteria, fungi and algae (ASTM D 6400-99 1976) have drawn the attention recently owing to the tremendous increase in the global demand for an alternative to nondegradable synthetic plastics. This recent trend is mainly attributed to the several detrimental qualities associated with synthetic plastics as they are xenobiotics and recalcitrant to biodegradation (Flechter 1993). Further plastics also produce toxic substances on disposal by incineration (Atlas and Bartha 1993) and cause higher waste accumulation in the landfills and marine environments besides polluting the environment.

Polyvinyl alcohol (PVA) with its carbon-carbon backbone, being water soluble can be biodegraded under both aerobic and anaerobic conditions (Suzuki et al. 1973; Watanabe et al. 1976; Sakazawa et al. 1981; Shimao et al. 1983; Mori et al. 1996; Matsumura et al. 1993) and therefore finds application in the manufacture of carriers used in delivery system for chemicals such as fertilizer, pesticides (Premraj and Doble 2005), in the textile, papercoating and chemical industries (Qian et al. 2004) and also as the biodegradable backbone in sugar and fatty acidbranched polymers (Tokiwa et al. 2000). The annual world production of PVA is about 0.65 million tons/year, and a 
large amount of the used and discarded PVA also poses a significant waste problem (Tokiwa et al. 2001). In natural environments, the distribution and number of microorganisms with the ability to degrade PVA are limited compared to those that can degrade aliphatic polyesters like polyhydroxyalkanoates (Tokiwa et al. 2001). Nevertheless, microorganisms capable of degrading PVA are not ubiquitous but are distributed in specific environmental niches (Lee and Kim 2003). In fact, activated sludge was reported as the source of PVA-degrading Sphingomonas sp. (Vaclavkova et al. 2007). Only very few bacteria were found to demonstrate abilities for PVA degradation. They include Pseudomonas O-3 (Suzuki et al. 1973), Pseudomonas sp. (Shimao et al. 1984, 1986, 1996; Watanabe et al. 1975, 1976; Sakai et al. 1981, 1985a, b), Alcaligenes faecalis (Matsumura et al. 1993) and Bacillus megaterium (Mori et al. 1996). Among fungi, Penicillium sp. has also been reported to produce PVA-degrading enzyme (Qian et al. 2004).

Linear low-density polyethylene (LLDPE) is the common name for copolymers of ethylene with $\alpha$-olefins: butene, hexene, octene and 4-methyl-1-pentene (Prasad 1998). They have good resistance to chemicals and ultraviolet radiation and hence can be used to make thinner films with better environmental stress-cracking resistance. The degradability of synthetic plastics like polyolefins can be augmented by adding biodegradable components to the polymer material (Griffin 1980, 2007) making the polymeric blends easily susceptible to microbial attack.

The mineralization processes in the marine environment are performed mainly by extracellular enzymes elaborated by in situ microorganisms (Belanger et al. 1997). Unlike other heterotrophic bacteria, Vibrio sp. ubiquitous to the marine aquatic environments produce an arsenal of extracellular hydrolytic enzymes (Raghul and Sarita 2011), which aid these microorganisms in surviving adverse and stressful environmental conditions, playing a pivotal role in the recycling of organic carbon and nitrogen compounds (Belanger et al. 1997) in the marine environments, thereby making available scarce C-sources.

Given that Vibrio sp. are the dominant heterotrophic bacteria in the marine environments along the west coast of India (Chandrasekaran et al. 1984), it is anticipated that they may have a role in the mineralization of organic sediments and other biodegradable materials disposed into coastal waters of marine environment. Hence, this investigation was undertaken with the intention to isolate PVA-degrading Vibrio sp. and develop an appropriate consortium toward efficient degradation of polyvinyl alcohol-low linear density polyethylene (PVA-LLDPE) plastic blends. This study is the first report of its kind that deals with marine vibrios for degradation of synthetic plastic blend films.

\section{Materials and methods}

\section{Collection of sediment samples}

Sediment samples were collected from the benthic zones of different marine environments like estuary, salt pans, mangroves, back waters and coastal waters, along southwest $\left(9.9^{\circ} \mathrm{N} 76^{\circ} \mathrm{E}\right)$ and east $\left(8.76^{\circ} \mathrm{N} 78^{\circ} \mathrm{E}\right)$ coast regions of India. The sediments from the backwaters were collected from a depth of 8 meters using a Peterson grab, while benthic sediments from the mangroves and salt pans were collected using a 2-mm-diameter corer (Raghul and Sarita 2011). The collected sediment samples were stored in sterile containers and transported to laboratory under refrigerated conditions. Samples were stored at $4{ }^{\circ} \mathrm{C}$ until use.

Isolation of PVA-degrading microorganisms

Microorganisms capable of degrading polyvinyl alcohol (PVA) from sediments were isolated by growing the microbial isolates in a mineral salts agar medium supplemented with PVA as sole source of carbon (Mori et al. 1996). Isolates which showed a clearance zone around the patched colony after flooding with iodine-boric acid solution were considered to have PVA-degrading ability (Finley 1961), and four strains that showed maximal PVAdegrading activities were selected, characterized, identified and used for further studies.

\section{Identification of PVA-degrading microorganisms}

\section{Biochemical characterization}

Morphological, physiological and biochemical characteristics of the selected strains were determined and segregated to genus level according to Bergey's manual of systematic bacteriology (Buchanan and Gibbons 1974). Besides Gram staining, marine oxidation/fermentation reaction $(\mathrm{MOF}$ test) and cytochrome oxidase tests, Hi-Vibrio identification system (Himedia, Mumbai, India) with 12 biochemical tests (Voges Proskauers's test, arginine dihydrolase test, $1 \%$ salt tolerance test, ONPG test, citrate utilization test, ornithine, mannitol, arabinose, sucrose, glucose, salicin and cellobiose utilization tests) enabled classification of the isolates according to Alsina and Blanch (1994). The extracellular enzyme productions were detected by plate assays for amylase (Furniss et al. 1978), caseinase (Kazanas 1968), lipase (Furniss et al. 1978), cellulase (Kasing et al. 2000), pectinase (Hankin et al. 1971), xylanase (Anuradha et al. 2007), alginase (Furniss et al. 1978), DNase (Zierdt and Golde 1970), gelatinase (Furniss et al. 1978) and phosphatase (Nautiyal 1999). 


\section{Genotypic characterization}

Genomic DNA was isolated, purified (Sambrook et al. 2000) and a portion of the $16 \mathrm{~S}$ rDNA amplified using a primer pair (Shivaji et al. 2000; Reddy et al. 2000, 2002a, b). The PCR products were purified by gene clean kit (Bangalore Genei, Bangalore, India) and sequenced by ABI Prism 310 genetic analyzer using the big dye terminator kit (Applied Biosystems, USA). Sequences were compared with the 16S rDNA sequences in the public nucleotide databases at National Center for Biotechnology Information (NCBI) (http://www.ncbi.nlm.nih.gov) using BLAST (Basic Local Alignment Search Tool) (Altschul et al. 1990), aligned and the phylogenetic tree constructed by the neighbor-joining method (Saitou and Nei 1987) using MEGA5: Molecular evolutionary genetics analysis (MEGA) software version 5.0. The TN84 distance (Tajima and Nei 1984) was used with 1,000 bootstrap.

Development of a Consortium of PVA degraders

Among the isolates that showed maximal PVA-degrading abilities, four strains were selected and developed as a mixed consortium for the degradation of PVA-LLDPE blended films. The individual isolates of the consortium were grown, in $50 \mathrm{ml}$ of nutrient broth (Himedia, Mumbai) at $\mathrm{pH} 7.0 \pm 0.3$, overnight at $37^{\circ} \mathrm{C}$, at $120 \mathrm{rpm}$, on an Orbitek shaker (Scigenics, India). The cells were then harvested by centrifugation at $5,000 \mathrm{rpm}(2,292 \mathrm{~g})(2-16 \mathrm{~K}$, Sigma, Germany) for $20 \mathrm{~min}$, washed with physiological saline and suspended in the same $\left(\mathrm{OD}_{660}=1\right)$. Later, all the cell suspensions were pooled and homogenized. A $5 \mathrm{ml}$ of this pooled culture $\left(\mathrm{OD}_{660}=1\right)$ was used as inoculum. All the selected bacterial strains were deposited at Microbial Culture Collection, Microbial Genetics Lab, Dept. of Biotechnology, Cochin University of Science and Technology, Cochin, India.

\section{Preparation of PVA-LLDPE blends}

Film-grade LLDPE (LL20FS010) (Reliance Industries Ltd, Mumbai, India) and industrial-grade hot water-soluble polyvinyl alcohol (Rolex Chemical Industries, Mumbai, India) were blended in Thermo HAAKE Polylab System (Germany) equipped with a pair of roller rotors at $195^{\circ} \mathrm{C}$. The density of the LLDPE sample is $0.920 \mathrm{~g} / \mathrm{cm}^{3}$. Molecular formula of polyvinyl alcohol is $\left(\mathrm{C}_{4} \mathrm{H}_{10} \mathrm{O}\right)_{\mathrm{n}}$, having a molecular weight of 17,300 and its viscosity at $4 \%$ concentration in water at $20^{\circ} \mathrm{C}$ is $3 \mathrm{mPa}$ s.

Rotor rpm was maintained at 50, and LLDPE was added first followed by PVA. PVA-LLDPE plastic-blended films were designated as L0, L5, L10, L15, L20, L25 and L30 for pure LLDPE and those with 5, 10, 15, 20, 25 and $30 \%$ of
PVA, respectively. The blends were compression-molded into sheets with a mold and an electrically heated hydraulic press.

Biodegradation of PVA-LLDPE blends by the consortium

Biodegradation of PVA-LLDPE blends by the consortium were conducted according to ASTM D 5247-92 (1992) in $50 \mathrm{~mL}$ of PVA minimal medium (Mori et al. 1996) with PVA-LLDPE plastic blends taken in conical flasks, with the strips acting as the sole source of carbon. The inoculated flasks were incubated in an Orbitek environmental shaker (Scigenics Pvt. Ltd, Chennai, India) at $37^{\circ} \mathrm{C}$ and $120 \mathrm{rpm}$ for a period of 15 weeks. Samples were drawn at regular intervals and analyzed for PVA degradation. The medium without the inoculum with corresponding PVALLDPE plastic blends treated similarly was used as control.

Analytical procedures

\section{Tensile strength analysis}

Tensile strength of the PVA-LLDPE blends was measured at regular intervals using Universal Testing Machine (Shimadzu Autograph AG-I Series, Netherlands). The change in tensile strength after 15 weeks of experiment was analyzed according to ASTM D 882-97 (1997).

Statistical analysis

The statistical evaluations were done by ANOVA using InStat (Ver.2.04a) computer program, where $\mathrm{p}$ values $<0.05$ were considered significant and graphs were plotted using Excel 2007 (Microsoft Corporation, Redmond, USA). All the experiments were repeated thrice.

\section{Scanning electron microscopy (SEM)}

The PVA-LLDPE plastic films from the shake flask experiments were observed by Scanning Electron Microscope (JEOL Model JSM-6390LV, USA) and compared with the control.

\section{Results and discussion}

Isolation and characterization of PVA-degrading microorganisms

Preliminary screening of the 56 isolates obtained from the different marine sediment samples designated as Vibrio sp., resulted in segregation of 48 as PVA degraders. They were 


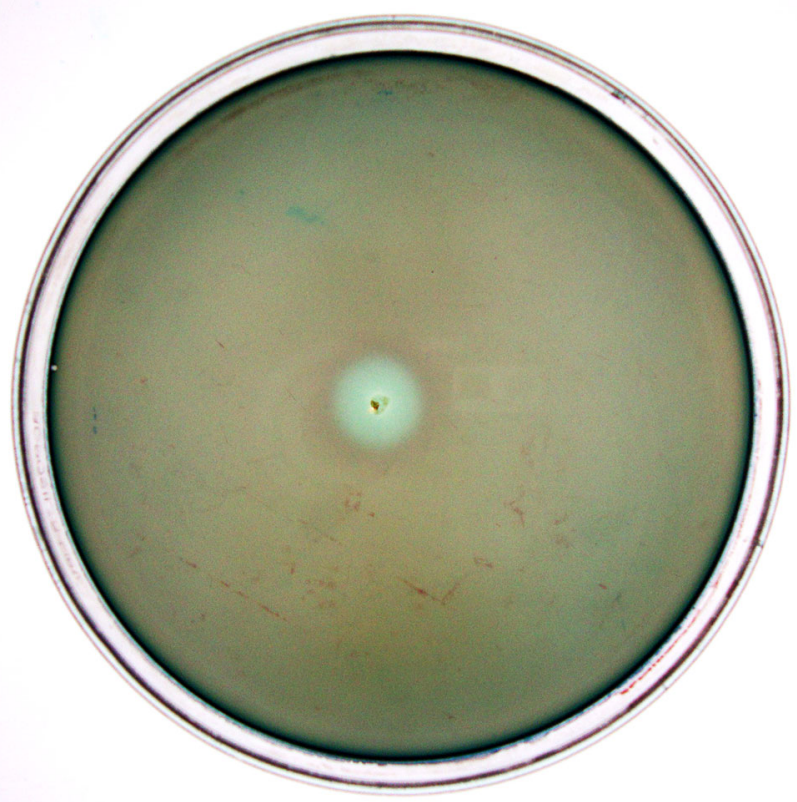

Fig. 1 Zone of clearance surrounding the colony of $V$. alginolyticus strain BTTC10 on PVA agar plates after flooding with iodine-boric acid solution indicating PVA degradation

short listed based on the zone of clearance developed surrounding the colony flooded with iodine-boric acid solution, indicating their PVA-degrading ability on PVA mineral agar plates (Fig. 1). Among these four strainsBTTV4, BTTC10, BTTC27 and BTTN18 with maximal clearance zones were selected to form the consortium, characterized and identified.

Benthic sediments of marine environments are usually ubiquitous and harbor diverse range of microorganisms which produce exoenzymes facilitating total mineralization of organic and inorganic substances of plant and animal origin which gets sedimented over a period of time. In addition, the voluminous garbage including xenobiotics dumped into aquatic environments by public as a convenient method of disposing solid wastes are also attacked by the benthic microorganisms in such a manner that there is no serious damage to the aquatic ecosystem reported so far. This unique phenomenon in aquatic systems particularly in the marine benthic sediments is made feasible only by the unique exoenzymes synthesized and elaborated into the environment (Chandrasekaran and Rajeev Kumar 2002). Although several exoenzymes belonging to the class of polysaccharases, lipases and proteinases have been reported, PVA-degrading bacteria in the natural environment are not so widely known (Premraj and Doble 2005). In this context the results of the present study strongly indicated the potential of benthic vibrios for PVA degradation. It may be noted that PVA degradation by Vibrio sp. has not been previously reported. In the present study, degradation was studied in simple minimal agar medium using only PVA as sole C-source with the halo zone around the colony, indicating the presence of the degrading enzyme (Mori et al. 1996). In literature, it was reported that Pseudomonas vesicularis required thiamine, in addition to three other amino acids like tyrosine or phenylalanine, isoleucine and cystine for PVA degradation (Hashimoto and Fujita 1985). Similarly, Sphingomonas sp. isolated from activated sludge required pyrroloquinoline quinine (PQQ) and a growth factor to aid in their degradation (Vaclavkova et al. 2007). Interestingly, the selected strains of Vibrio sp. were observed to exhibit their PVA-degrading ability on the plate in less than $24 \mathrm{~h}$ at $37{ }^{\circ} \mathrm{C}$ without the need for any enrichment or additional supplements suggesting their novel ability for degrading polymeric substances that are naturally occurring in marine environment.

The biochemical characteristics and the exoenzyme pattern of the isolates (BTTV4, BTTC10, BTTC27 and BTTN18) comprising the consortium are given in Table 1. All isolates produced extracellular hydrolytic enzymes like DNase, lipase, gelatinase, caseinase and amylase. Vibrio sp. strain BTTV4 produced extracellular pectinase, while BTTC10, BTTC27 and BTTN18 were producers of extracellular cellulases. None of these strains could produce alginase, phosphatase or xylanase. Exoenzyme production in vibrios is well reported (Itoi et al. 2007; Maureen et al. 1977; Samuel and Gabriel 1981; Young and Broadbent 1982, Raghul and Sarita 2011); these enzymes play a central role in the recycling of organic carbon and nitrogen compounds in the marine environment. Hydrolytic enzymes such as amylases, caseinases, lipases, DNases, pectinases, cellulases and gelatinases exhibit the versatility of these heterotropic vibrios in utilizing several types of carbon sources as substrates. This also points to the scope of developing suitable consortia to find application in degradation of PVA blends with other polymers.

The partial sequence analysis of the 16S rDNA helped to identify strains BTTV4 and BTTN18 as $V$. parahaemolyticus and strain BTTC10 and BTTC27 as V. alginolyticus and their nucleotide sequences have been deposited in the GenBank database under accession numbers GU904007, GU904004, GU904005 and GU904006, respectively. A phylogenetic tree showing the phylogenic relationship between these 4 strains based on the partial 16S rDNA sequences was constructed and is shown in Fig. 2. It is observed that only strain BTTN27 grouped with the standard strains of $V$. alginolyticus, as also did BTTN18 with the standard strains of $V$. parahaemolyticus; while the strain BTTC10 identified as V. alginolyticus and BTTV4 identified as $V$. parahaemolyticus grouped separately. This clearly shows the divergence in this closely related group isolated from the marine environments. This diversity is also observed in the phenotypic characters of these isolates. 
Table 1 Biochemical characteristics of the Vibrio sp. comprising the consortium

+ : positive test; - : negative test; -ve: gram negative

Fig. 2 Phylogenetic tree showing the phylogenic relationship between the 4 Vibrio sp. strains (BTTC10, BTTN18, BTTC27 and BTTV4) based on their partial 16S rDNA sequences. Branch lengths are proportional to the number of substitutions per site. The tree is rooted by out-group $E$. coli (GU065251.1)

\begin{tabular}{|c|c|c|c|c|}
\hline Trait & $\begin{array}{l}\text { V. parahaemolyticus } \\
\text { strain BTTV4 }\end{array}$ & $\begin{array}{l}\text { V. alginolyticus } \\
\text { strain BTTC10 }\end{array}$ & $\begin{array}{l}\text { V. parahaemolyticus } \\
\text { strain BTTN18 }\end{array}$ & $\begin{array}{l}\text { V. alginolyticus } \\
\text { strain BTTC27 }\end{array}$ \\
\hline Cell morphology & Rod & Rod & Rod & Rod \\
\hline Gram reaction & $-\mathrm{ve}$ & $-\mathrm{ve}$ & $-\mathrm{ve}$ & $-\mathrm{ve}$ \\
\hline Oxidase test & + & + & + & + \\
\hline MOF test & + & + & + & + \\
\hline Voges Proskaur's test & - & + & - & - \\
\hline Arginine test & + & + & - & - \\
\hline Salt tolerance test & + & + & + & + \\
\hline ONPG test & - & - & - & - \\
\hline Citrate test & + & + & + & + \\
\hline Ornithine test & - & - & - & - \\
\hline Mannitol test & - & + & + & + \\
\hline Arabinose test & + & + & + & - \\
\hline Sucrose test & - & + & + & + \\
\hline Glucose test & + & + & + & + \\
\hline Salicin test & - & - & - & - \\
\hline Cellobiose test & - & - & - & - \\
\hline Caseinase & + & + & + & + \\
\hline Amylase & + & + & + & + \\
\hline Lipase & + & + & + & + \\
\hline Pectinase & + & - & - & - \\
\hline Cellulase & - & + & + & + \\
\hline Xylanase & - & - & - & - \\
\hline Alginase & - & - & - & - \\
\hline DNase & + & + & + & + \\
\hline Gelatinase & + & + & + & + \\
\hline Phophatase & - & - & - & - \\
\hline
\end{tabular}

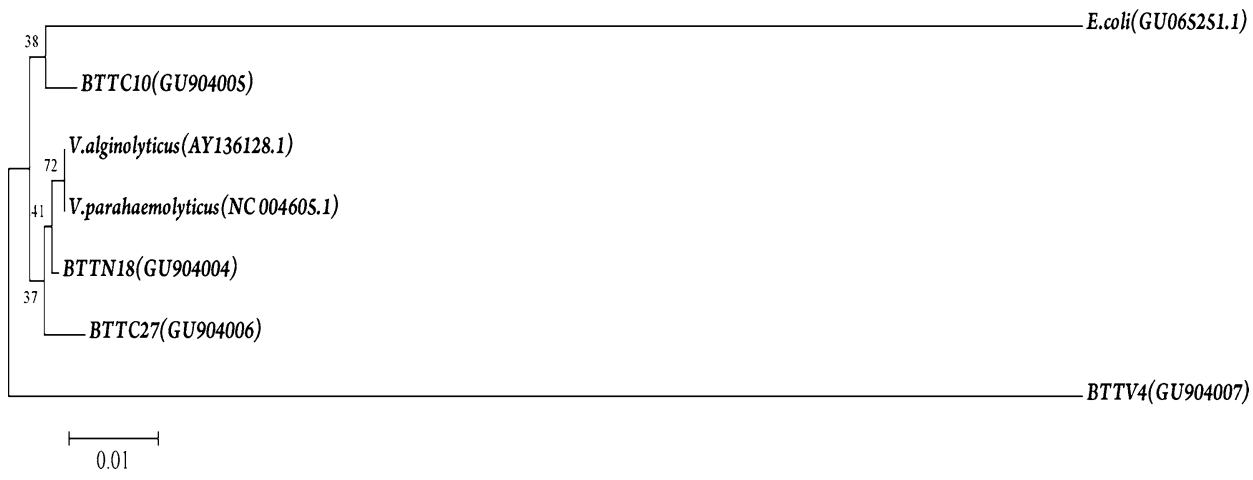

Microbial degradation of PVA-(LLDPE) blends

From the results presented in Fig. 3, based on the measurement of the tensile strength, it was inferred that the developed bacterial consortium comprising the strains V. parahaemolyticus (BTTV4 and BTTN18) and strain as $V$. alginolyticus (BTTC10 and BTTC27) hold potential to degrade the PVA-LLDPE plastic films at the end of the 15 -week period. The pattern of variation observed with the tensile strength of the strips compared with the control (untreated) testify that degradation took place in the films over the 15-week-extended incubation under shake flask condition. Further, the percentage loss in tensile strength was recorded to be greater (about $20 \%$ ) in PVA-LLDPE plastic films with 25 and $30 \%$ PVA compared with others at the end of the 15-week incubation (Fig. 4). The decline in the tensile strength with the increase in PVA content in the strips indicated ability of the bacterial consortium for 
enhanced degradation of the PVA-LLDPE strips facilitated by the PVA component, which could have served as a possible carbon source. The reduction in the film tensile

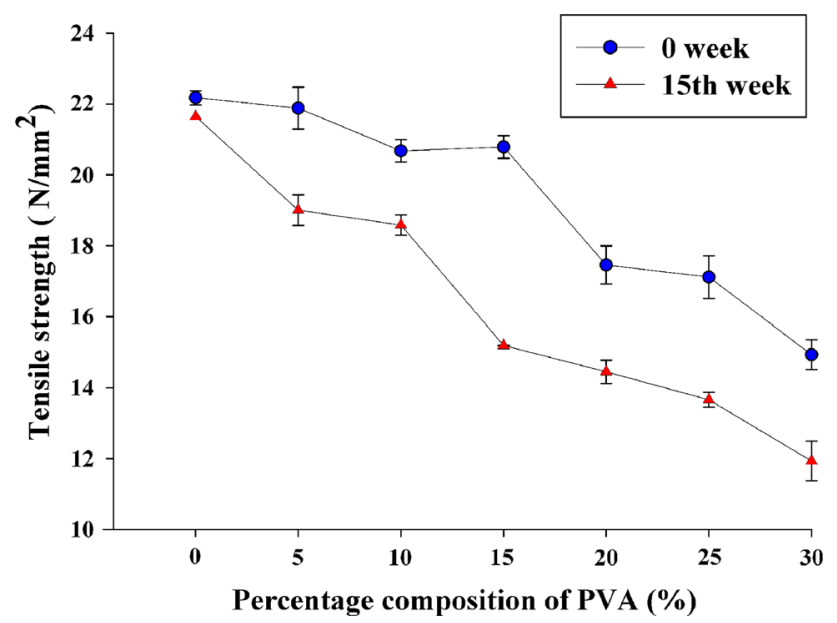

Fig. 3 Tensile strength of LLDPE-PVA films after 15 weeks of degradation by the consortium of PVA-degrading Vibrio $\mathrm{sp}$ $(P<0.001)$ strength could be attributed to the loss of PVA owing to its degradation by microbial activity.

The scanning electron micrograph obtained for the blended plastic film with varying concentrations of PVA testified that the bacterial consortium utilized the PVA in the film and effected degradation. The SEM micrograph for the film prepared with $30 \%$ PVA before and after treatment is represented in Fig. 5 a, b. The micrograph (Fig. 5a) indicated that the LLDPE-PVA blends prior to biodegradation exhibited rough surface with no characteristic surface defects. Whereas, cracks and grooves were visible on the surface of the LLDPE-PVA blend film after 15 weeks of incubation with bacterial consortium evidencing the deterioration in the film surface due to the action of the microbial PVA-degrading enzymes (Fig. 5b). The SEM analysis and tensile strength analysis both testify to the biodegrading ability of the consortium of PVA degraders. Earlier studies on PVA-degrading mixed cultures revealed that degradation was mostly due to co-metabolism by two PVA-degrading strains, Bacillus megaterium (BX1) and PN19 (Mori et al. 1996). The growth factor required for the PVA degradation in Sphingomonas sp. was supplied by
Fig. 4 Percentage loss in tensile strength after 15 weeks of biodegradation by the consortium of PVA-degrading Vibrio sp. Values are average of three separate experiments. $* P<0.001$ when compared to control (L0). L0-100\% LLDPE; L5-95\% LLDPE + $5 \%$ PVA; L10$90 \%$ LLDPE + $10 \%$ PVA; L15-85 \% LLDPE + $15 \%$ PVA; L20-80 \% LLDPE + $20 \%$ PVA; L 25-75 \% LLDPE + $25 \%$ PVA and L $30-70 \%$ LLDPE $+30 \%$ PVA

Fig. 5 Scanning electron micrograph $(\mathrm{X} 1,500)$ of the surface of LLDPE-PVA (L30$70 \%$ LLDPE + $30 \%$ PVA) films. a Control b after 15 weeks of degradation by the consortium of PVA-degrading Vibrio sp.. The bar is $50 \mu \mathrm{m}$
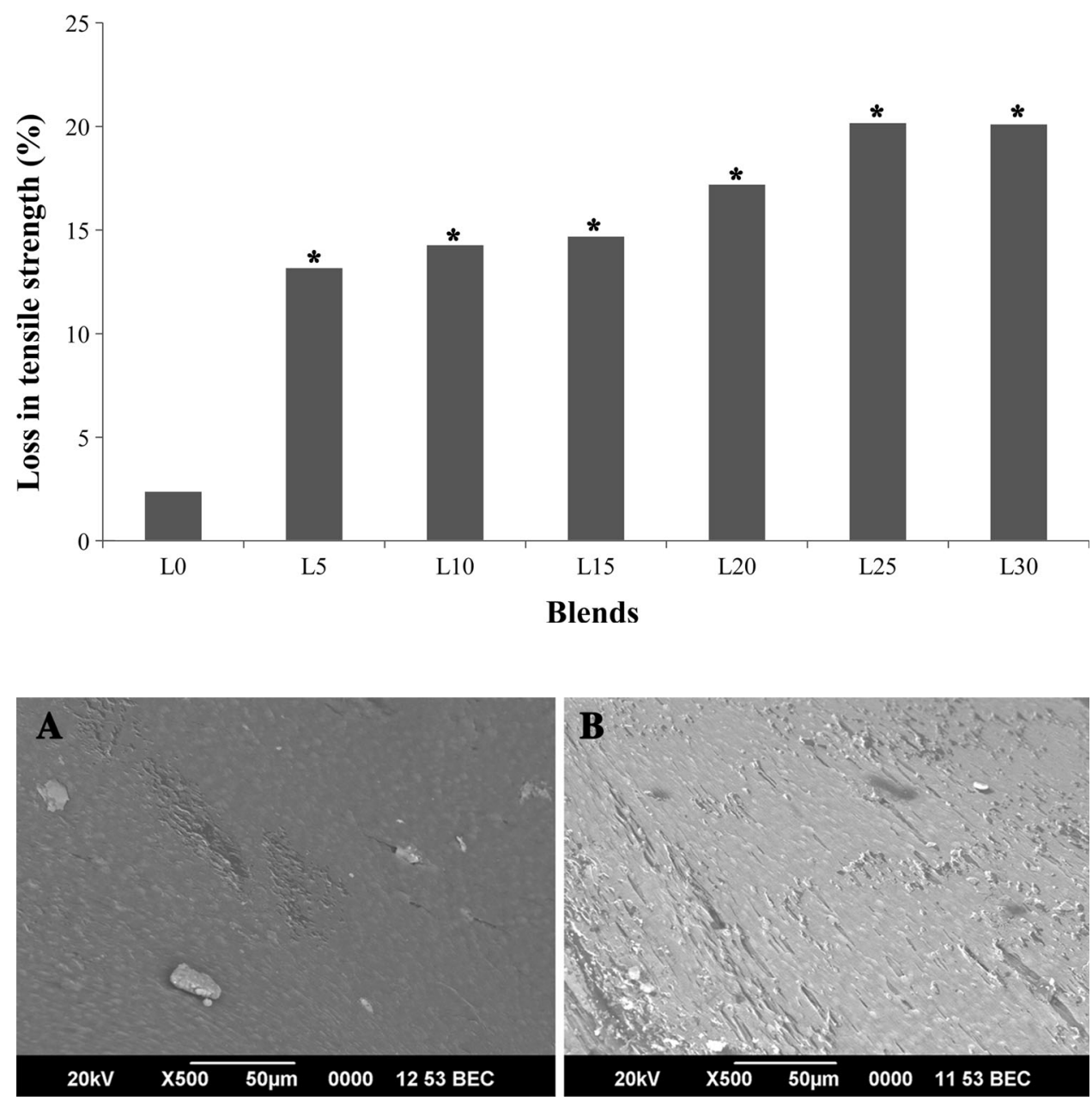
another bacteria Rhodococcus erythropolis, indicating the symbiotic nature of these degrading microbes (Vaclavkova et al. 2007). It was reported that during the symbiotic utilization of polyvinyl alcohol by the mixed cultures of Pseudomonas putida (VM15A) and Pseudomonas sp. (VM15C) the PVA-degrading enzyme was produced by the strain VM15C while VM15A supported growth of VM15C on PVA (Sakazawa et al. 1981). These observations of earlier investigators suggest that a consortium with two or more microbes would be more effective than a single organism in degrading this kind of synthetic polymeric substrates.

\section{Conclusion}

To conclude, a consortium of PVA-degrading vibrios was developed for the degradation of PVA-LLDPE blends. It is speculated that they were probably induced by the PVA to elaborate degradative enzymes to support this capability. Indeed, it was observed that the ability of these benthic microbes to degrade the PVA- LLDPE film did not necessitate specific nutritional requirements. Although there is a distinct possibility of co-metabolism on the PVA-LLDPE plastic blends, no attempt was made in this direction at present and would be considered in future studies. Thus, marine benthic vibrios with a repertoire of extracellular enzymes and unique characteristics like PVA-degrading ability can be used for bioremediation of pollutants and in solid waste management, particularly in handling synthetic polymers such as PVA-blended plastic films.

Acknowledgments This study was supported by grant from Department of Ocean Development, Government of India (No.DOD/ 11-MRDF/1/29/06).

\section{Abbreviations \\ PVA Polyvinyl alcohol \\ LLDPE Low linear density polyethylene}

\section{References}

Alsina M, Blanch AR (1994) A set of keys for biochemical identification of environmental Vibrio species. J Appl Bacteriol 76(1):79-85. doi:10.1111/j.1365-2672.1994.tb04419.x

Altschul SF, Gish W, Miller W, Myers EW, Lipman DJ (1990) Basic local alignment search tool. J Mol Biol 215(3):403-410. doi: 10.1016/S0022-2836(05)80360-2

Anuradha P, Vijayalakshmi K, Prasanna ND, Sridevi K (2007) Production and properties of alkaline xylanases from Bacillus sp. isolated from sugarcane fields. Curr Sci 92:1283-1286

ASTM D 6400-99 (1976) Standard specification for compostable plastics, annual book of standards
ASTM D 5247-92 (1992) Standard test method for determining the aerobic biodegradability of degradable plastics by specific microorganisms

ASTM D 882-97 (1997) Standard test method for tensile properties of thin plastic sheeting

Atlas RM, Bartha R (1993) Microbial ecology. Fundamentals and applications, 3rd edn. The Benjamin/Cummings Publication Company, Redwood City

Belanger C, Desrosiers B, Lee K (1997) Microbial extracellular enzyme activity in marine sediments: extreme $\mathrm{pH}$ to terminate reaction and sample storage. Aquat Microbiol Ecol 13:187-196

Buchanan RE, Gibbons NC (1974) Bergey's manual of systematic bacteriology, 8th edn. Williams \& Wilkins Co., Baltimore

Chandrasekaran M, Rajeev Kumar S (2002) Marine microbial enzymes in biotechnology. In: Doelle H, DaSilva E (eds) Encyclopedia of life support systems (EOLSS), developed under the auspices of the UNESCO. EOLSS publishers, Oxford

Chandrasekaran M, Lakshmanaperumalsamy P, Chandramohan D (1984) Occurrence of vibrios during fish spoilage. Curr Sci 52:31-32

Finley JH (1961) Spectrophotometric determination of polyvinyl alcohol in paper coatings. Anal Chem 33:1925-1927. doi: 10.1021/ac50154a044

Flechter A (1993) PHA as natural, biodegradable polyesters. In: Chen GQ (ed) Plastics from bacteria and for bacteria. Springer Verlag, New York, pp 77-93

Furniss AL, Lee JV, Donovan TJ (1978) The Vibrios. Public Health Laboratory Service monograph, vol 11. Maidstone Public Health Laboratory, Maidstone

Griffin GJL (1980) Synthetic polymers and the living environment. Pure Appl Chem 52:399-407

Griffin GJL (2007) Degradation of polyethylene in compost burial. J Polym Sci Polym Symp 57(1):281-286

Hankin L, Zucker M, Sanda DC (1971) Improved solid medium for the detection and enumeration of pectolytic bacteria. Appl Microbiol 22:205-209

Hashimoto S, Fujita M (1985) Isolation of a bacterium requiring three amino acids for polyvinyl alcohol degradation. J Fermentation Technol 63:471-474

Itoi S, Kanomata Y, Koyama Y, Kadokura K, Uchida S, Nishio T, Oku T, Sugita H (2007) Identification of a novel endochitinase from a marine bacterium Vibrio proteolyticus strain No. 442. Biochem Biophys Acta 1774(9):1099-1107

Kasing A, Jong BC, Salleh MA (2000) Screening and isolation of a cellulolytic and amylolytic Bacillus from sago pith waste. J Gen Appl Microbiol 46:263-267. doi:10.2323/jgam.46.263

Kazanas N (1968) Proteolytic activity of microorganisms isolated from freshwater Fish. Appl Microbiol 16:128-132

Lee JA, Kim MN (2003) Isolation of new and potent poly(vinyl alcohol)-degrading strains and their degradation activity. Polymer Degrad Stabil 81:303-308

Matsumura S, Kurita H, Shimokobe H (1993) Anaerobic biodegradability of polyvinyl alcohol. Biotechnol Lett 15:749-754. doi: 10.1007/BF01080150

Maureen F, Nitkowski Dudley S, Graikoski JT (1977) Identification and characterization of lipolytic and proteolytic Bacteria Isolated from Marine Sediments. Mar Pollut Bull 8(12):276-279

Mori T, Sakimoto M, Kagi T, Sakai T (1996) Isolation and characterization of a strain of Bacillus megaterium that degrades poly (vinyl alcohol). Biosci Biotechol Biochem 60(2):330-332. doi:10.1271/bbb.60.330

Nautiyal SC (1999) An efficient microbiological growth medium for screening phosphate solubilizing microorganisms. FEMS Microbiol Lett 170:265-270. doi:10.1111/j.1574-6968.1999.tb13383.x

Prasad A (1998) A quantitative analysis of low density polyethylene and linear low density polyethylene blends by differential 
scanning calorimetry and fourier transform infrared spectroscopy methods. Polym Eng Sci 38(10):1716-1728

Premraj R, Doble M (2005) Degradation of polymers. Indian J Biotechnol 4:186-193

Qian D, Du G, Chen J (2004) Isolation and culture characterization of a new polyvinyl alcohol-degrading strain: penicillium $\mathrm{sp}$. WSH02-21. World J Microbiol Biotechnol 20:587-591. doi: 10.1023/B:WIBI.0000043172.83610.08

Raghul SS, Sarita GB (2011) Extracellular enzyme profile and seasonal distribution of extracellular enzyme production in Vibrio sp. inhabiting marine benthic environments along coastal waters of India. Indian J Geo-Marine Sci 40:826-833

Reddy GSN, Aggarwal RK, Matsumoto GI, Shivaji S (2000) Arthrobacter flavus sp. nov., a psychrophilic bacterium isolated from a pond in McMurdo Dry Valley, Antarctica. Int J Syst Evol Microbiol 50:1553-1561. doi:10.1099/ijs.0.02131-0

Reddy GSN, Prakash JSS, Matsumoto GI, Stackebrandt E, Shivaji S (2002a) Arthrobacter roseus sp. nov., a psychrotolerant bacterium isolated from an Antarctic cyanobacterial mat sample. Int $\mathrm{J}$ Syst Evol Microbiol 52:1017-1021

Reddy GSN, Prakash JSS, Vairamani M, Prabhakar S, Matsumoto GI, Shivaji S (2002b) Planococcus antarcticus and Planococcus psychrophilus sp. nov. isolated from cyanobacterial mat samples collected from ponds in Antarctica. Extremophiles 6:253-261. doi:10.1007/s00792-001-0250-7

Saitou N, Nei M (1987) The neighbor-joining method: a new method for reconstructing phylogenetic trees. Mol Biol Evol 4:406-425

Sakai K, Morita M, Hamada N, Watanabe Y (1981) Purification and properties of oxidized polyvinyl alcohol-degrading enzyme. Agric Biol Chem 45:63-71

Sakai K, Hamada N, Watanabe Y (1985a) A new enzyme, betadiketone hydrolase : a component of a poly (vinyl alcohol)degrading enzyme preparation. Agric Biol Chem 49:1901-1902

Sakai K, Hamada N, Watanabe Y (1985b) Purification and properties of oxidized polyvinyl alcohol hydrolase with an acidic isoelectric point. Agric Biol Chem 49:827-833

Sakazawa C, Shimao M, Taniguchi Y, Kato N (1981) Symbiotic utilization of polyvinyl alcohol by mixed culture. Appl Environ Microbiol 41:261-267

Sambrook J, Fritsch EF, Maniatis T (2000) Molecular Cloning: a laboratory manual, 3rd edn. Cold Spring Harbor Laboratory Press, New York

Samuel KCO, Gabriel MU (1981) Pectic enzyme activities of bacteria associated with rotted onions (Allium cepa). Appl and Environ Microbiol 42(4):585-589

Shimao M, Saimoto H, Kato N, Sakazawa C (1983) Properties and roles of bacterial symbionts of polyvinyl alcohol utilizing mixed cultures. Appl Environ Microbiol 46:605-610
Shimao M, Fukuta I, Kato N, Sakazawa C (1984) Mixed continuous cultures of polyvinyl alcohol-utilizing symbionts Pseudomonas putida VM15A and Pseudomonas sp. Strain VM15C. Appl Environ Microbiol 48(4):751-754

Shimao M, Ninomiya K, Kuno O, Kato N, Sakazawa C (1986) Existence of a novel enzyme, pyrroloquinoline quinine dependent polyvinyl alcohol dehydrogenase, in a bacterial symbiont, Pseudomonas sp. strain VM15C. Appl Environ Microbiol 51:268-275

Shimao M, Tamogami T, Nishi K, Harayama S (1996) Cloning and characterization of the gene encoding pyrroloquinoline quinine dependent polyvinyl alcohol dehydrogenase of Pseudomonas sp. strain VM15C. Biosci Biotechnol Biochem 60:1056-1062

Shivaji S, Bhanu NV, Aggarwal RK (2000) Identification of Yersinia pestis as the causative organism of plague in India as determined by $16 \mathrm{~S}$ rDNA sequencing and RAPD-based genomic fingerprinting. FEMS Microbiol Lett 189:247-252. doi:10.1111/ j.1574-6968.2000.tb09238.x

Suzuki T, Ichihara Y, Yamada M, Tonomura K (1973) Some characteristics of Pseudomonas O-3 which utilizes polyvinyl alcohol. Agric Biol Chem 37:747-756

Tajima F, Nei M (1984) Estimation of evolutionary distance between nucleotide sequences. Mol Biol Evol 1:269-285

Tokiwa Y, Raku T, Kitagawa M, Kurane R (2000) Preparation of polymeric biosurfactant containing sugar and fatty acid esters. Clean Prod Processes 2:108-111. doi:10.1021/ma981451v

Tokiwa Y, Kawabata G, Amnat J (2001) A modified method for isolating polyvinyl alcohol-degrading bacteria and study of their degradation patterns. Biotechnol Lett 23:1937-1941. doi: 10.1023/A:1013785817554

Vaclavkova T, Ruzicka J, Julinova M, Vicha R, Koutny M (2007) Novel aspects of symbiotic polyvinyl alcohol biodegradation. Appl Microbiol Biotechnol 76:911-917. doi:10.1007/s00253007-1062-1

Watanabe Y, Morita M, Hamada N, Tsujisaka Y (1975) Formation of hydrogen peroxide by a polyvinyl alcohol degrading enzyme. Agric Biol Chem 39:2447-2448

Watanabe Y, Hamada N, Morita M, Tsujisaka Y (1976) Purification and properties of a polyvinyl alcohol-degrading enzyme produced by a strain of Pseudomonas. Arch Biochem Biophys 174(2):575-581

Young DB, Broadbent DA (1982) Biochemical characterization of extracellular proteases from Vibrio cholera. Infect Immun 37(3):875-883

Zierdt CH, Golde DW (1970) Deoxyribonuclease positive Staphylococcus epidermidis strains. Appl Microbiol 20:54-57 